Bangladesh Med Res Counc. Bull 2018; 44: 109-112

DOI: http://dx.doi.org/10.3329/bmrcb.v44i2.38706

\title{
Stenting in Takayasu's Arteritis: A Case Report
}

\author{
Hussain MZ*, Islam MT, Karim T, Alam S, Bhuiyan MMR, Bhadra S \\ Department of Paediatric Cardiology, Bangabandhu Sheikh Mujib Medical University, Dhaka, Bangladesh
}

\begin{abstract}
Takayasu arteritis (TA), also known as idiopathic medial aortopathy or pulseless disease, is a granulomatous large vessel vasculitis that predominantly affects the aorta and its major branches. It may also affect the pulmonary arteries. The exact cause is not well known but the pathology is thought to be similar to giant cell arteritis. There is segmental and patch granulomatous inflammation of the aorta which results in stenosis, thrombosis and aneurysm formation. Half of the patients present with an initial systemic illness whereas the other $50 \%$ present with late-phase complications. There is a strong female predominance ( $\mathrm{F}: \mathrm{M} \sim 9: 1)$, an increased prevalence in Asian populations, and it tends to affect younger patients ( $<50$ years of age). The typical age of onset is at around 15-30 years of age. Here, it is reported a case of 9 years old girl with Takayasu's arteritis.
\end{abstract}

\section{Introduction}

Takayasu's arteritis (TA) is a chronic, idiopathic, inflammatory vascular disease that mainly affects large vessels such as aorta and its main branches. ${ }^{1}$ It is common in Asia and usually affects adolescents and young women. ${ }^{2}$ It is a form of granulomatous arteritis, which affects large and medium arteries, primarily the aorta and its large branches as well as proximal portions of pulmonary, coronary, and renal arteries. Initially, there are mononuclear cell infiltrations in the adventitia and granulomas with Langerhans cells in the media followed by disruption of the elastin layer and subsequent massive medial and intimal fibrosis. These lesions result in segmental stenosis, occlusion, dilatation and aneurysmal formation in the affected vessels. Diminished or absent pulses are present in $84-96 \%$ of patients, associated with limb claudication and blood pressure discrepancies between the two arms. ${ }^{3}$

This report describes a 9 years old girl who presented with occasional chest pain, palpitation and failure to thrive. She was later diagnosed as having Takayasu`s disease.

\section{Case report}

The girl presented with occasional chest pain, palpitation for one and half years, easy fatigability and regular leg pain. She had feeble peripheral pulses except in carotid. Pulse rate was $100 / \mathrm{min}$, it was regular of low volume and condition of the vessel wall was normal with a $\mathrm{BP}$ difference in both arms (Rt. arm-76/52mmHg, Lt. arm $59 / 38 \mathrm{mmHg}$ ). BP not recordable in both lower limbs. Systemic examination was unremarkable. ESR raised-35 $\mathrm{mm}$ in 1st hour, CRP-markedly elevated- $71 \mathrm{mg} / \mathrm{l}$. CBC, renal function, fasting lipid profile were normal, her chest $\mathrm{x}$-ray showed mildly enlarged heart shadow in transverse diameter. Echocardiography revealed enlarged heart with mild mitral and tricuspid regurgitation, moderate coarctation of aorta and severe LV systolic dysfunction (EF 25\%).

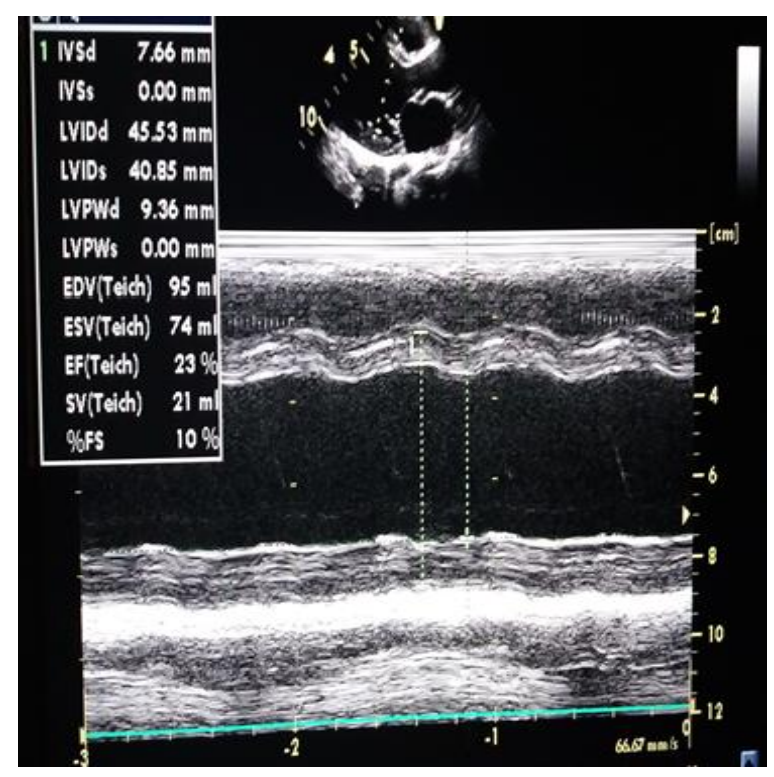

Figure 1: Echocardiography: Severe LV systolic dysfunction (EF$25 \%)$ 
Her CT Aorto-pulmonary Angiogram showed hypoplastic distal arch with moderate to severe narrowing of descending and abdominal aorta and non visualization of origin of left common carotid and left subclavian artery. Root of Aorta $18.8 \mathrm{~mm}$, Asc. aorta - 20.7mm, Arch prox. $18.8 \mathrm{~mm}$, distal Arch- 9.9mm, DTA - 4.1mm, abdominal Aorta $-3.8 \mathrm{~mm}$ (figure 2).

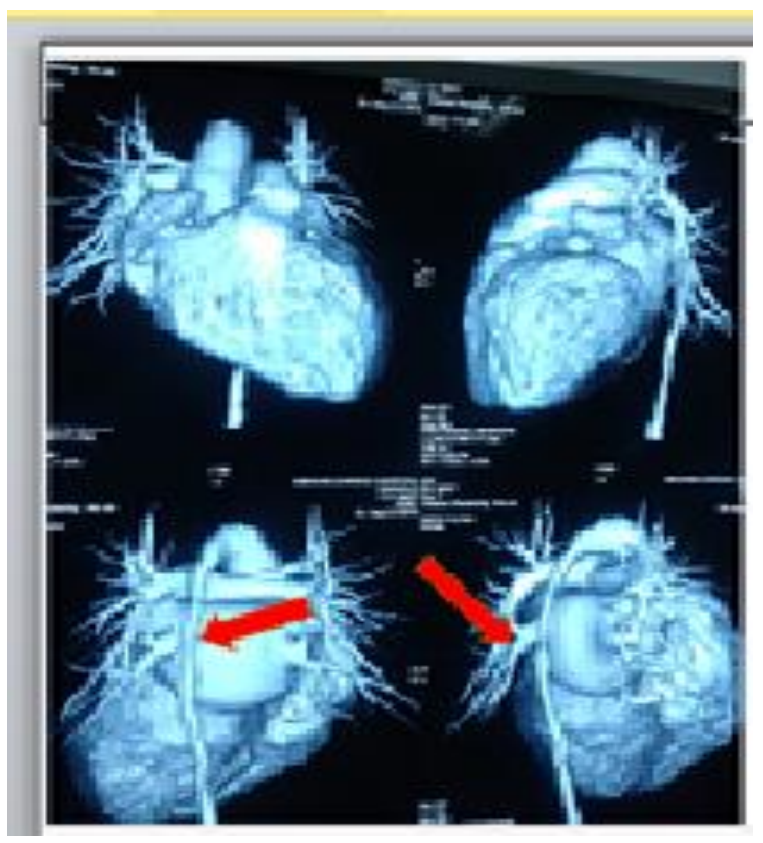

Figure 2: CT Angiogram

On cardiac catheterization coronary arteries are both well visualized. Brachiocephalic trunk shows diffusely narrowing with stenosis at origin of RCCA, LCCA is not visualized. LSA origin is visible. Diffuse narrowing of the aorta below the LSA, down to the bifurcation of the iliac trunk.

So, angiographic classification is a combination of type I \& type III Takayasu Arteritis (Involvement of part of aortic arch and its branches and thoracic and abdominal aorta).

The patient was treated by balloon angioplasty with stenting (Epic TM self expanding nitinol Stent of $100 \mathrm{~mm}$ X 10mm). Pre dilatation was done with Tyshak Balloon $8 \mathrm{~mm}$ X $3 \mathrm{~cm}$ and Post dilatation was done with Tyshak Balloon $10 \mathrm{~mm} \mathrm{x}$ $3 \mathrm{~cm}$. (figure: 3 )

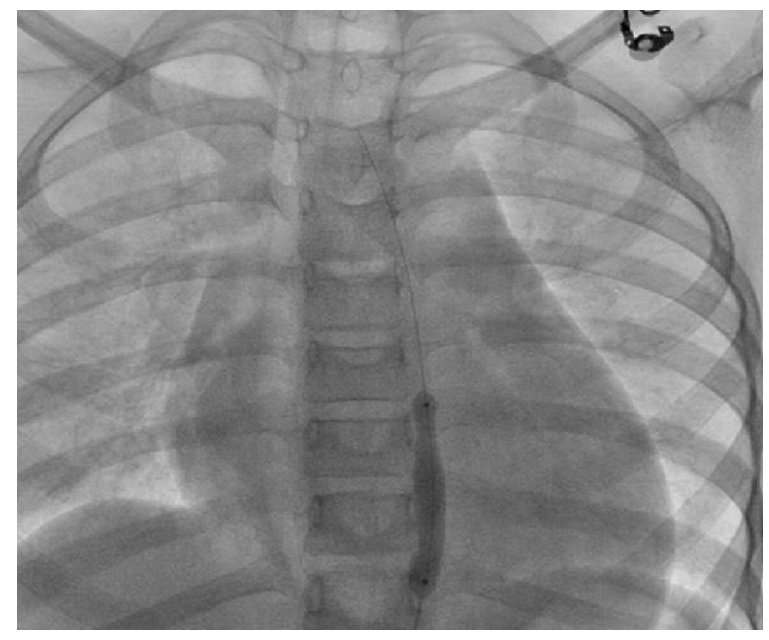

Figure 3a: Pre dilatation was done with Tyshak Balloon $8 \mathrm{~mm} \mathrm{X}$ $3 \mathrm{~cm}$

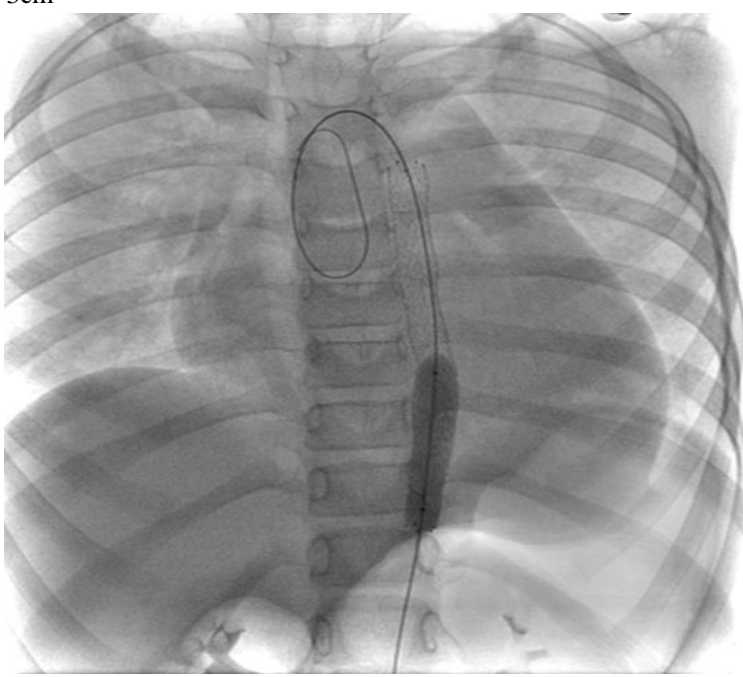

Figure 3b: Tenting (Epic TM self expanding nitinol Stent of $100 \mathrm{~mm}$ X 10mm).

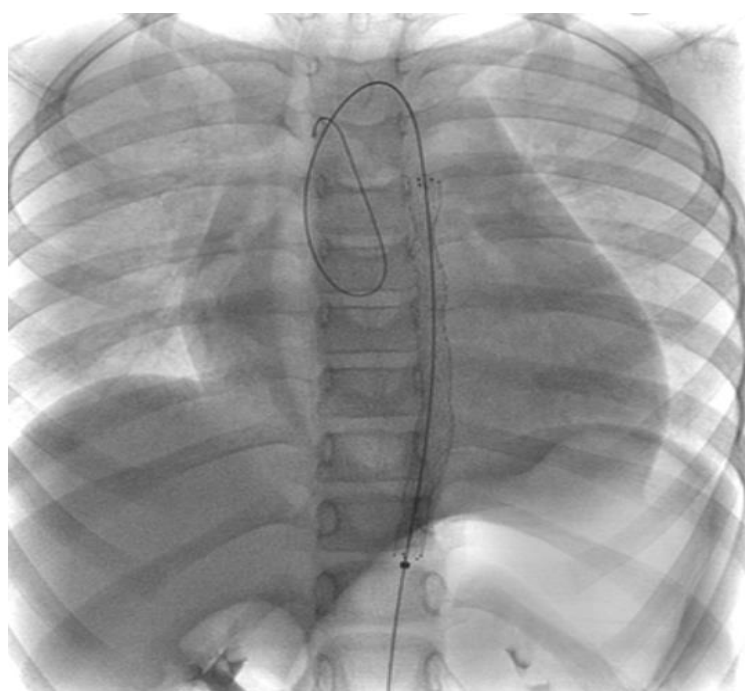

Figure 3c: Post stenting dilataion with Tyshak Balloon 10mm X $3 \mathrm{~cm}$. 
After stenting she was heparinized and post procedural period was uneventful. Following the placement of stent, her upper limb pulses were relatively of good volume with a heart rate of 120/min. Subsequently she was treated with Tab. Ecosprin $(5 \mathrm{mg} / \mathrm{kg})$, Tab. Clopidogrel (75mg/day), Prednisolone $(1 \mathrm{mg} / \mathrm{kg} /$ day) and Inj. Methotrexate 40 unit/week subcutaneously. Post procedural Echocardiography shows reasonably good flow in Aorta and EF 46\%. On final follow up ejection fraction increased to $62 \%$ with reasonably good flow through the stented segment.

\section{Discussion}

Takayasu's arteritis (TA) was first reported by M. Takayasu, a Japanese ophthalmologist in the year $1908 .^{5,6}$ TA commonly affects young adults in the second and third decade of life with female:male ratio 1.3:1 in India. ${ }^{6}$ It is a chronic granulomatous necrotizing vasculitis predominantly affecting the aorta with its branches, pulmonary and coronary arteries. $^{5,6}$ Though the exact pathogenesis of the arteritis is still unknown, tuberculosis, streptococcal infections, rheumatoid arthritis and other collagen vascular diseases have been debated as it's a etiology in the past. Recently more emphasis has been given on an immunopathological cause. ${ }^{8,9}$ Recent studies strongly suggest association of interleukin-6 and RANTES (regulated on activation, normal $\mathrm{T}$ cell expressed and secreted) in the pathogenesis of the disease process. ${ }^{7}$ Histopathology of the involved vessels suggests that the initial site of inflammation is around the vasa vasorum which are small arteries in the media and adventitia., ${ }^{4,6}$

Clinical manifestations of TA are nonspecific. The clinical course of the disease is divided into an early active inflammatory phase and late chronic phase. The active phase lasts for weeks to months and may have a remitting and relapsing course. It is characterized by systemic disease with symptoms of fever, general malaise, night sweats, loss of appetite, weight loss, headaches, dizziness, arthralgia, skin rashes, etc. The acute phase does not occur in all patients, but constitutional symptoms are often seen in children with TA. It should be highlighted that the correct diagnosis of TA is seldom made in the early phase. Evidence of vessel inflammation such as tenderness along arteries, bruits, and aneurysm may point to the diagnosis of TA. ${ }^{6}$ The late chronic phase is the result of arterial stenosis and/ occlusion and ischemia of organs. The disease is classified based on the site of involvement:

\begin{tabular}{ll}
\hline Type I: & Aortic arch involvement \\
Type II: & Thoracoabdominal involvement \\
Type III: & Diffuse involvement \\
Type IV: & Pulmonary involvement \\
Type V: & Aneurysmal type \\
\hline
\end{tabular}

The site of arterial disease determines its clinical presentation. There can be dizziness or syncope due to the decreased perfusion to the brain, which can be aggravated by neck movements. This leads to classical drooping position of the head. A classical bruit can be heard over the stenosed carotids. Cardiac involvement in the form of myocardial infarction, valvular pathology, conduction system block or coronary artery involvement can be seen. Pulmonary vasculitis can lead to pulmonary hypertension and ventilation perfusion abnormalities. The other associated findings are renal artery stenosis and musculoskeletal involvement in the form of rheumatoid arthritis and ankylosing spondylitis. ${ }^{10}$ Patients with TA should be assessed for the anatomical pattern of the disease and evaluated for hypertension and its complications. Preoperatively, clinical features suggestive of carotid involvement, such as dizziness, syncope on extension of head and carotid bruit should be evaluated. ${ }^{11}$ Measurement of blood pressure and proper documentation of all pulses deserves special attention in such patients. NIBP monitoring using the oscillometric method and pulse oximetry can provide simple and reliable blood pressure readings even in patients with pulseless extremities. ${ }^{12}$ Steroids are the mainstay of management in aortoarteritis. These patients require antihypertensives. There also need of anticoagulants and antiplatelets.

Incapacitating arterial occlusion requires surgical intervention..$^{10}$ Nearly $30 \%$ of TA patients require surgery, usually for large-vessel vasculitis that warrants $\mathrm{CABG}$ or replacement of the aortic root or valve. ${ }^{13,14}$ Clinically significant coronary artery disease has been treated with angioplasty, although $\mathrm{CABG}$ has usually been preferred..$^{1,15-17}$ 
If possible, surgery should be delayed until the acute phase of the disease has passed.

As is evidenced by our patient's presentation and course of disease a multidisciplinary approach is needed which is beneficial for our patient.

\section{Conclusion}

This report highlights that takayasu arteritis can only present with nonspecific symptoms. The importance of modern day imaging techniques such as CT, MRI and angiography, can often be of paramount importance to confirm diagnosis and extent of the pathology. Steroid is the mainstay of treatment but not curative, however relapses are frequent, and $25 \%$ of the patients develop progressive disease despite conventional treatment. Angioplasty and stenting may be required in the management of Takayasu arteritis.

\section{References}

1. Kerr GS, Hallahan CW, Giordano J, Leavitt RY, Fauci AS, Rottem M, et al. Takayasu arteritis. Ann Intern Med 1994;120:919-29.

2. Arend WP, Michel BA, Bloch DA, Hunder GG, Calabrese LH, Edworthy SM, et al. The American College of Rheumatology 1990 criteria for the classification of Takayasu arteritis. Arthritis Rheum 1990;33:1129-34.

3. Johnston SL, Lock RJ, Gompels MM. Takayasu arteritis: areview. J Clin Pathol 2002;55:481-86

4. Kaushik S, Gupta A, Gupta V, Jain S, Lal V. Retinal arterial occlusion in Takayasu's arteritis. Indian J Ophthalmol. 2005;53:194-96

5. Chun YS, Park SJ, Park IK, Chung H, Lee J Retina. 2001; 21:132-40. The clinical and ocular manifestations of Takayasu arteritis.

6. Kothari SS. Takayasu's arteritis in children- a review. Paediatr Cardiol. 2002;9:4-23.
7. Noris M, Diana E, Gamba S, Bonazzola S, Remuzzi G. Interleukin-6 and RANTES in Takayasu Arteritis. Circulation. 1999;100:55-60.

8. Das D, Mondal KK, Ray B, Chakraborti A. A case of unusual presentation of takayasu arteritis. Indian J Ophthalmol. 2010 Mar-Apr;58:148-150.

9. Hawth JC, Cunnigham FG, Young B K. Takayasu's syndrome In pregnancy. Obstetrics and Gynaecology 1977; 50: 373-75.

10. Stoelting RK, Dierdorf SF: Anesthesia and CoExisting Disease, 4th edition. New York, Churchill Livingstone, 2002

11. Dutta B, Pandey R, Darlong V, Garg R. Lowdose spinal anesthesia for a parturient with Takayasu's arteritis undergoing emergency caesarean section. Singapore Med J 2010; 51: e113.

12. Chawla R, Kumarvel V, Girdhar KK, et al. Oximetry in pulseless disease [letter]. Anesthesia 1990; 45: 992.

13. Sato EI, Lima DN, Espirito Santo B, Hata F. Takayasu arteritis. Treatment and prognosis in a university center in Brazil. Int J Cardiol 2000;75 Suppl 1:S163-6.

14. Giordano JM. Surgical treatment of Takayasu's arteritis. Int J Cardiol 2000;75 Suppl 1:S123-8.

15. Hashimoto Y, Tanaka M, Hata A, Kakuta T, Maruyama Y, Numano F. Four years follow-up study in patients with Takayasu arteritis and severe aortic regurgitation; assessment by echocardiography. Int J Cardiol 1996;54 Suppl:S173-76.

16. Seko Y, Sato O, Takagi A, Tada Y, Matsuo H, Yagita $\mathrm{H}$, et al. Restricted usage of $\mathrm{T}$-cell receptor Valpha-Vbeta genes in infiltrating cells in aortic tissue of patients with Takayasu's arteritis. Circulation 1996;93:1788-90.

17. Maksimowicz-McKinnon K, Clark TM, Hoffman GS. Limitations of therapy and a guarded prognosis in an American cohort of Takayasu arteritis patients. Arthritis Rheum 2007; 56:1000-09.

*Correspondence: Mohd Zahid Hussain, Department of Paediatric Cardiology, Bangabandhu Sheikh Mujib Medical University, Dhaka, Bangladesh; e-mail: z.hussain71@yahoo.com 